\title{
Uso de antipiréticos en Pediatría
} Use of antipyretics in pediatrics

Valeria Gómez-Toscano

La fiebre es un signo que se manifiesta junto con múltiples enfermedades infantiles; por tanto, es motivo frecuente de consulta al pediatra o médico general. Acompaña lo mismo a enfermedades triviales y de alivio espontáneoque a las graves que ponen en peligro la vida. La causa no necesariamente es infecciosa, puede tener un fondo inmunológico o neoplásico, pero su presencia indica actividad inflamatoria.

El síndrome febril se define como "la elevación térmica del cuerpo como respuesta específica, mediada por el control central, ante una agresión determinada". Se ha llegado al consenso internacional para considerar fiebre a la temperatura rectal mayor a $38^{\circ} \mathrm{C}$, temperatura axilar superior a $37.5^{\circ} \mathrm{C}$ o temperatura timpánica superior a $38.2^{\circ} \mathrm{C} .{ }^{1}$

Tratamiento específico de la fiebre

La aspirina y los antiinflamatorios no esteroideos (AINEs) disminuyen la temperatura elevada, mientras que la temperatura corporal normal se afecta levemente. La disminución de la temperatura suele ocurrir por incremento en la disipación causado por la vasodilatación de los vasos sanguíneos superficiales y puede acompañarse de sudoración profusa. El mecanismo de acción antipirético se basa en la inhibición de síntesis y liberación de prostaglandinas a nivel hipotalámico. Casi todas las prostaglandinas, excepto la I2, son piretógenas. Paradójicamente, la intoxicación con salicilatos puede producir elevación de la temperatura corporal por aumento del consumo de oxígeno y de la tasa metabólica, aparentemente por desacople de la fosforilación oxidativa.

Los antiinflamatorios no esteroideos representan la piedra angular del tratamiento de la fiebre en pacientes pediátricos, aunque existen otros
Recibido: 16 de abril de 2018

Aceptado: 17 de octubre de 2018

Correspondencia

Valeria Gómez- Toscano

valeria_172884@yahoo.com

Este artículo debe citarse como

Gómez-Toscano V. Indicación de antipiréticos a pacientes pediátricos. Acta Pediatr Mex. 2018;39(6):385-388. 
medicamentos antitérmicos que también se mencionan enseguida.

\section{Analgésicos antitérmicos y antiinflamatorios no esteroideos}

- Derivados del paraaminofenol: paracetamol y fenacetina (esta última en desuso). Su acción se basa en la inhibición de las prostaglandinas a nivel central.

- Derivados del pirazol: metamizol o dipirona magnésica. Son inhibidores centrales de las prostaglandinas e inactivadores del receptor sensibilizado.
- Antiinflamatorios no esteroideos: salicilatos, ibuprofeno, naproxeno, ácido mefenámico, nimesulida, indometacina, diclofenaco, ketorolaco y dexketoprofeno trometamol. La acción de los antiinflamatorios no esteroideos se basa en la inhibición de la enzima ciclooxigenasa a nivel central y periférico, con la consiguiente reducción de la síntesis de prostaglandinas y tromboxanos. Todos los antiinflamatorios no esteroideos son inhibidores no selectivos de la enzima ciclooxigenasa. Cuadro 1

Cuadro 1. Relación de fármacos antipiréticos, dosis, consideraciones y efectos secundarios

\section{Fármaco y dosis}

Paracetamol (analgésico y antipirético)

-VO: $10-15 \mathrm{mg} / \mathrm{kg}$ cada $4-6 \mathrm{~h}$

-VR: $15-30 \mathrm{mg} / \mathrm{kg}$ cada $4-6 \mathrm{~h}$

-IV: $15 \mathrm{mg} / \mathrm{kg}$ cada $4-6 \mathrm{~h}$ (dosis máxima 4 g c/24 h), >50

$\mathrm{kg}: 1 \mathrm{~g} \mathrm{c} / 6 \mathrm{~h}$

Ibuprofeno

-VO: 5-10 mg/kg cada 6-8 h (dosis máxima 40 mg/kg/día)

-VO: $10-15 \mathrm{mg} / \mathrm{kg}$ cada 4-6 h

Diclofenaco

-VO: $0.5-1.5 \mathrm{mg} / \mathrm{kg}$ cada $8 \mathrm{~h}$

-VR: $0.5-1 \mathrm{mg} / \mathrm{kg}$ cada $8 \mathrm{~h}$

Naproxeno

-VO y VR: 10 mg/kg/día cada 12 h (dosis máxima 1.5 g/día)

\section{Consideraciones y efectos secundarios}

No tiene efecto antiinflamatorio ni antiagregante plaquetario. Sin erosiones ni úlceras gastrointestinales. Riesgo de hepatotoxicidad.

Muy seguro a dosis terapéuticas, por lo que es el analgésico antipirético más empleado a nivel mundial.

Derivado del ácido propiónico, inhibidor no selectivo de la ciclooxigenasa, inhibe la adherencia y agregación de neutrófilos. A dosis altas disminuye la producción de citocinas y la liberación de enzimas lisosomales.

Analgésico, antiinflamatorio.

Antipirético.

Antiagregante plaquetario reversible.

Riesgo de úlcera péptica menor que otros AINEs. Riesgo de nefrotoxicidad.

Analgésico, antiinflamatorio y antipirético. Efecto antiagregante plaquetario prolongado (6-7 días).

Analgésico, antiinflamatorio y antipirético.

Riesgo de sangrado gástrico.

Efecto espasmolítico.

Analgésico, antiinflamatorio y antipirético.

Riesgo de úlcera péptica, perforación o hemorragia gastrointestinal, dolor epigástrico, cefalea, náusea, vómito, diarrea, flatulencia, constipación, dispepsia, dolor abdominal, melena, hematemesis, estomatitis ulcerosa, exacerbación de colitis y de enfermedad de Crohn; edema periférico moderado, hipertensión arterial sistémica, vértigo, somnolencia, tinnitus. Efectos secundarios a nivel rectal como tenesmo, proctitis. 
Gómez-Toscano V. Antipiréticos

Cuadro 1. Relación de fármacos antipiréticos, dosis, consideraciones y efectos secundarios (continuación)

Fármaco y dosis
Ketorolaco
-VO, IV o IM: $0.75 \mathrm{mg} / \mathrm{kg}$ cada $6 \mathrm{~h}$ (dosis máxima $60 \mathrm{mg}$ )

Nimesulida

-VO: $3-5 \mathrm{mg} / \mathrm{kg}$ divididos en 2 tomas

Indometacina

-VO: 1.5-2.5 mg/kg/día cada 6-8 h (dosis máxima $4 \mathrm{mg} /$ $\mathrm{kg} / \mathrm{día})$

Ácido mefenámico

-VO: >14 años: 500 mg/8 h o 250 mg/6 h

Dexketoprofeno Trometamol

-VO: adultos: 12.5 mg/4-6 h ó 25 mg/8 h, dosis máxima $75 \mathrm{mg} /$ día

-IM o IV: adultos: 50 mg/8-12 h, dosis máxima 150 mg/día

Metamizol

-VO (magnésico o sódico): 15-40 mg/kg cada 6-8 h

-VR (magnésico): 15-20 mg/kg cada 4-6 h

-IV (magnésico): $11 \mathrm{mg} / \mathrm{kg} /$ dosis; (sódico): 1 a 14 años:

$5-8 \mathrm{mg} / \mathrm{kg} /$ dosis cada $6 \mathrm{~h}$

-IM (magnésico): $11 \mathrm{mg} / \mathrm{kg} /$ dosis; (sódico): 3 a 11 meses:

5-9 mg/kg/dosis máximo cada 6 h; 1 a 14 años: 5-8 mg/

$\mathrm{kg} /$ dosis cada $6 \mathrm{~h}$.

\section{Consideraciones y efectos secundarios}

Potente analgésico, antipirético y antiinflamatorio comparable a los opiáceos, aparentemente sin mayores efectos secundarios que otros antiinflamatorios no esteroideos. Sin embargo, entre los efectos adversos documentados están insuficiencia renal aguda, úlceras, hemorragias digestivas, perforación gástrica y duodenal, y reacciones de hipersensibilidad.

Inhibición preferente de la COX-2, aunque no exclusiva. Inhibición de la traslocación de la fosfodiesterasa tipo IV e inhibición de la liberación de histamina de los basófilos y células cebadas. Se asocia con daño hepático que puede ser fatal. Otros efectos adversos asociados son colestasis, coagulopatía, síndrome de Reye, rash, urticaria/angioedema, edema periférico, estomatitis, parestesias, púrpura trombocitopénica, eritema pigmentado fijo, irritabilidad, cefalea o disminución en la agudeza visual. Su uso en neonatos se ha asociado con daño renal. Ha sido catalogado por la FDA como de "Most DILI (drug induced liver injury) concern". Por lo anterior, no se justifica su uso en niños cuando existen alternativas más seguras como el paracetamol, y no se autorizó su uso en países desarrollados, o se retiró del mercado en aquellos países desarrollados donde había sido previamente autorizado. Aún así, todavía se utiliza en países en vías de desarrollo como el nuestro.

Analgésico, antipirético y antiinflamatorio no esteroideo. Sus efectos tóxicos, como trastornos de la coagulación, cefalea, úlcera gástrica, sangrado gastrointestinal y nefrotoxicidad, limitan sus indicaciones en tratamientos crónicos.

Fenamato. Analgésico y antipirético.

Riesgo de diarrea, sangrado del recto o erupción cutánea.

Disminuye la síntesis de prostaglandinas por inhibición de la ciclooxigenasa.

Riesgo de náuseas, vómitos, dolor abdominal, dispepsia, diarrea y dolor en el lugar de inyección.

Analgésico potente y antipirético no antiinflamatorio derivado de la pirazolona que se había considerado con alto índice de toxicidad, lo que llevó a su retiro del mercado en Estados Unidos en 1977. Más aún, se le consideró como inaceptable para uso terapéutico en 2003. Sin embargo, en un reciente metaanálisis del año 2015, se encontraron menos efectos adversos que los analgésicos opioides, RR=0.79 (IC 0.79-0.96); tampoco se encontraron diferencias importantes entre metamizol y placebo, paracetamol (RR=1.08, IC 0.69-1.68), ácido acetilsalicílico ( $R R=0.80, I C$ 0.44-1.45) y AINEs (RR=0.91, IC 0.79-1.05). En el caso de metamizol VS paracetamol, se reportó mayor incidencia de hipotensión en los pacientes tratados con metamizol con un $\mathrm{RR}=3.6$ (IC 1.07-11.27). En este metaanálisis no se encontraron eventos adversos serios, agranulocitosis o muerte. Algunos de los efectos adversos menores reportados en general son dolor en el sitio de aplicación, vómito, vértigo, mareo, cefalea, sudoración, fatiga o somnolencia. Para uso a corto plazo, se considera una alternativa segura a otros analgésicos de mayor uso. 


\section{Recomendaciones para la indicación de antiinflamatorios no esteroideos}

Elección del antiinflamatorio no esteroideo o antipirético y la vía adecuada en cada cuadro febril, dependiendo de cada paciente, inicio y duración del AINE, lesión gastrointestinal previa existente y experiencia:

- Con rapidez de acción: metamizol, ketorolaco, dexketoprofeno trometamol, ibuprofeno.

- De mayor duración: diclofenaco retard (de liberación prolongada) o naproxeno.

- Con mayor poder antiinflamatorio: naproxeno, diclofenaco.

- Con mayor poder analgésico: metamizol, ketorolaco, paracetamol y dexketoprofeno.

- Menos gastrolesivos: paracetamol, metamizol, dexketoprofeno trometamol, ibuprofeno.

\section{Características del antipirético ideal}

1. Resultado rápido y eficaz para reducir la fiebre por lo menos $1^{\circ} \mathrm{C}$.

2. Disponible en forma líquida y supositorio.

3. Baja tasa de efectos secundarios con dosis terapéuticas y baja toxicidad cuando se toma en sobredosis.

4. Baja incidencia de interacción con otros medicamentos y rara contraindicación en pediatría.

5. Seguro y rentable.

\section{LECTURAS RECOMENDADAS}

1. http://www.cenetec.salud.gob.mx/descargas/gpc/CatalogoMaestro/imss_350_13_fiebresinsignosdefocalizacion/imss_350_13_fiebresinsignosdefocalizaciongrr.pdf

2. Barrios SA. Fiebre: actualización en el uso de antipiréticos. Precop SCP. 11(4): 26-35.

3. Barba CC, Martínez LD, Pérez TGP, López SE, Chavarría BLA, Ortiz MI. Comparación del efecto antipirético del ibuprofeno, metamizol, nimesulide y paracetamol en niños. Rev Mex Ped. 75 (1); 2008: 9-13.

4. Scholten AC, Berben SAA, Westmaas AH, van Grunsven PM, de Vaal ET, Rood PPM, et al. Pain management in trauma patients in (pre) hospital based emergency care: Current practice versus new guideline. Injury Int J Care Injured. 2015; 46: 798-806.

5. Ibáñez S, Morales Mas C, Calleja MA, Moreno PJ, Gálvez R. Terapéutica: Tratamiento del dolor. Formación continuada para farmacéuticos del hospital. Fundación promedic. 2.6. 118-45.

6. Travería CJ, Gili BT, Rivera LJ. Tratamiento del dolor agudo en el niño: analgesia y sedación. Protocolos diagnósticoterapéuticos de Urgencias Pediátricas SEUP-AEP.

7. Kötter $T$, da Costa BR, Fässier M, Blozik E, Linde K, Jüni P, et al. Metamizole-associated adverse events: a systematic review and meta-analysis. PLoS One. 2015; 10(4): e0122918.

8. Schönhöfer P, Offerhaus L, Herxheimer A. Dipyrone and agranulocitosis: What is the risk? Lancet. 2003; 361(9361): 968-9.

9. Thawani V, Sontakke S, Gharpure K. Nimesulide: The current controversy. Ind J Pharmacol. 2003; 35: 121-2.

10. Chen M, Suzuki A, Thakkar S, Yu K, Hu C, Tong W. DILIrank: the largest reference drug list ranked by the risk for developing drug-induced liver injury in humans. Drug Discov Today. 2016, 21(4): 648-653. 